\title{
Uso de revestimentos comestíveis adicionados de óleos essenciais na conservação de maçã e melão minimamente processados
}

\author{
Renata Fialho Teixeira, Caroline Dellinghausen Borges
}

https://doi.org/10.4322/mp.978-65-991393-5-2.c11

\section{Resumo}

Frutas minimamente processadas (MPs) são altamente perecíveis, tendo em vista o estresse fisiológico a que são submetidas durante o processamento. Revestimentos comestíveis adicionados de óleos essenciais (OEs) representam alternativas a serem utilizadas para inibir alterações indesejáveis, grande parte pelo potencial antimicrobiano e antioxidante que apresentam. Objetivou-se com esta revisão, relatar a influência da adição de OEs ou seus compostos ativos, em revestimentos comestíveis, nas características microbiológicas, físico-químicas e sensoriais de maçãs e melões MPs. A adição de OEs ou de seus compostos ativos aos revestimentos ocasionaram maior inibição do crescimento de diversos grupos de micro-organismos deteriorantes e patogênicos em maçã e melão MPs. O uso de maiores concentrações de OE ampliou o seu efeito antimicrobiano, dependendo do tipo de óleo adicionado. No entanto, alterações de cor e textura foram observadas mesmo na presença de agentes antiescurecimento e reticulantes nos revestimentos, como ácidos orgânicos e sais de cálcio. Embora os revestimentos exerçam barreira ao oxigênio e vapor de água, a incorporação de OEs em maiores concentrações foi associada ao aumento da reação de escurecimento, peroxidação lipídica e modificações estruturais nos tecidos. A aceitabilidade de frutas MPs revestidas na presença de OEs está condicionada a manutenção de seu sabor e aroma característicos. A partir dos dados coletados, é possível afirmar que o emprego em baixas concentrações de OEs, bem como, de seus compostos ativos em revestimentos comestíveis, são eficazes em manter a qualidade geral de maçãs e melões MPs.

Palavras-chave: antimicrobianos, compostos ativos, Cucumis melo L., Malus domestica B.

\section{Introdução}

O processamento mínimo de frutas e hortaliças é um ramo da indústria de alimentos com notável potencial de crescimento, alavancado pela crescente demanda dos consumidores por vegetais que apresentem qualidade, conveniência, praticidade e que sejam seguros para o consumo (ALZAMORA et al., 2016; COSTA et al., 2017). Os termos fresh-cut ou minimamente processados (MPs) têm sido empregados para definir vegetais que passam apenas por alterações físicas mantendo seu estado de frescor. O processamento mínimo inclui operações como seleção, lavagem, sanitização, descascamento, corte, drenagem, embalagem, seguidos do 
armazenamento refrigerado para comercialização (ARTÉS; GÓMEZ; ARTÉSHERNÁNDEZ, 2007; FONTES et al., 2008).

As frutas MPs são altamente suscetíveis a alterações decorrentes do estresse fisiológico a que são submetidas durante o processamento. Dentre os diversos processos metabólicos que as tornam mais perecíveis que as frutas inteiras são comumente citados o aumento das taxas de produção de etileno e atividade respiratória, degradação de lipídios das membranas celulares, reações oxidativas e de alteração de cor, formação de compostos secundários indesejáveis, alteração da síntese proteica e da composição de ácidos orgânicos e carboidratos, perda de água por evaporação e exsudação, alteração de textura, além do aumento da proliferação microbiana (BALDWIN; NISPEROS-CARRIEDO; BAKER, 1995; FONTES et al., 2008; KLUGE et al., 2016; OLIVAS; BARBOSA-CANOVAS, 2005). Muitas dessas respostas deletérias para a qualidade dos vegetais MPs ocorrem rapidamente após o estresse, enquanto outras podem demorar alguns dias para serem desencadeadas (MORETTI, 2007; PICCHIONI et al., 1994).

Uma alternativa promissora para minimizar os danos causados pelo processamento mínimo consiste na aplicação de revestimentos comestíveis à base de polissacarídeos, proteínas, lipídios ou combinação destes componentes. Segundo Cao, Fu e He (2007) e Santos et al. (2012), o uso de revestimentos auxilia na preservação dos vegetais por maiores períodos, mantendo a qualidade exigida pelos consumidores com características do fruto inteiro. Além disso, o revestimento comestível pode ser adicionado de ingredientes ativos, como agentes antiescurecimento, de firmeza, nutrientes e compostos antimicrobianos. Nesse sentido, tem sido avaliada a incorporação de óleos essenciais (OEs), ou seus compostos ativos na forma isolada, aos revestimentos, devido à redução da permeabilidade ao oxigênio através da matriz e inibição do crescimento de patógenos, dentre outros benefícios que apresentam, sendo uma alternativa ao uso de conservantes sintéticos (ROJAS-GRAÜ et al., 2007; SANTOS et al., 2012).

Em melões e maçãs MPs têm sido avaliados diferentes combinações de revestimentos à base de polissacarídeos como quitosana, alginato, pectina e goma gelana, adicionados de diferentes óleos essenciais, como OE de capim-limão, canela, cravo, tomilho e orégano (CHEVALIER et al., 2016; GUERREIRO et al., 2017; RAYBAUDIMASSILIA; MOSQUEDA-MELGAR; MARTÍN-BELLOSO, 2008; RAYBAUDI-MASSILIA et al., 2008; ROJAS-GRAÜ; TAPIA; MARTÍN-BELLOSO, 2008; SALVIA-TRUJILLO et al., 2015; SARENGAOWA et al., 2017). Diante disso, esta revisão tem por objetivo relatar a influência da adição de óleos essenciais ou seus compostos isolados, em revestimentos comestíveis, nas características microbiológicas, físico-químicas e sensoriais de maçãs e melões minimamente processados.

\section{Adição de óleos essenciais em revestimentos comestíveis aplicados a maçãs minimamente processadas}

A maçã (Malus domestica B.), pertencente à família Rosaceae, é uma fruta amplamente cultivada, consumida e apreciada no Brasil (FREIRE et al., 1994; MALDONADO et al., 2016). Sua utilização como produto MP representa uma forma de aproveitar excedentes de produção, além de agregar valor ao produto e propiciar a conveniência do consumo (FAGUNDES, 2009). Entretanto, maçãs MPs são altamente suscetíveis a alterações fisiológicas, principalmente, advindas da atividade enzimática em decorrência da exposição ao ar, o que compromete as características sensoriais e físico-químicas dos frutos, como reações de escurecimento, mudança na textura e aumento do crescimento microbiano (FONTES et al., 2008). Dessa forma, serão 
discutidos os principais efeitos observados pela adição de óleos essenciais ou seus compostos ativos em maçãs MPs revestidas.

\subsection{Avaliação microbiológica}

A atividade antimicrobiana de alguns OEs e seus compostos isolados, incluindo óleo de orégano e capim-limão, é atribuída a vários compostos terpenoides e fenólicos, que também em forma pura demonstram atividade antibacteriana ou antifúngica (BURT, 2004; FRIEDMAN; HENIKA; MANDRELL, 2002). Nychas, Tassou e Skandamis (2003) relataram que o modo de ação de cada OE depende de sua concentração, em que doses mais baixas podem inibir enzimas associadas à produção de energia e, doses mais elevadas podem precipitar proteínas. Rojas-Graü et al. (2007) verificaram que os revestimentos comestíveis à base de alginato e purê de maçã contendo OEs de capim-limão (1,0 e 1,5\%) e orégano (0,3 e 0,5\%), controlaram de modo eficaz o crescimento de bolores, leveduras e bactérias psicrófilas em maçãs MPs durante 21 dias.

O uso do revestimento comestível à base de alginato $(2,0 \%)$ contendo ácido málico (2,5\%), sem a adição de OEs avaliado por Raybaudi-Massilia et al. (2008) foi eficaz em reduzir a proliferação da Escherichia coli O157:H7, inoculada na superfície das maçãs MPs. Entretanto, a incorporação de OEs e seus compostos isolados a esse revestimento em maiores concentrações, possibilitou aumentar a inibição de microorganismos patogênicos e deteriorantes, criando um efeito antimicrobiano melhorado, que se estendeu durante 30 dias de armazenamento. A adição dos OEs de capimlimão e canela $(0,7 \%)$ e seus compostos ativos isolados, citral e cinamaldeído $(0,5 \%)$, respectivamente, foram os antimicrobianos mais efetivos em estender a vida útil das maçãs MPs, enquanto OEs de capim-limão, canela e cravo-da-índia em menores concentrações $(0,3 \%)$ apenas mantiveram as características físico-químicas dos frutos, comparado ao grupo controle (RAYBAUDI-MASSILIA et al., 2008).

A incorporação de OE de capim-limão $(0,5$ e 1,0\%) em um revestimento à base de nanoemulsões de alginato (2,0\%), reduziu as contagens microbianas logo após a sua aplicação e inibiram completamente a microflora natural das maçãs MPs durante 14 dias de armazenamento. Cabe salientar ainda que os revestimentos de alginato com OE de capim-limão na escala nano, exibiram uma melhor e mais rápida inativação dos micro-organismos, incluindo atividade bactericida contra $E$. coli inoculada, em comparação com os revestimentos de alginato convencionais (SÁLVIA-TRUJILLO et al., 2015).

Atividade antimicrobiana contra E. coli O157:H7, Salmonella Typhimurium e Listeria monocytogenes foi relatada a partir da utilização de OEs de tomilho, canela e orégano $(0,05, \quad 0,35$ e $0,65 \%)$ em um revestimento comestível de alginato $(1,29 \%)$ (SARENGAOWA et al., 2017). Destacou-se a adição de OE de tomilho (0,05 e 0,35\%) em função da maior redução das contagens totais de maçãs MPs, quando comparado à incorporação de $0,65 \%$ após 12 dias de armazenamento. Esse efeito pode ser relacionado à parede celular do tecido do fruto que se torna gradualmente mais macia com o passar do tempo, bem como, à alta concentração de OE que pode acelerar o processo de deterioração das maçãs MPs. O revestimento de alginato com 0,05\% de OE de tomilho foi considerado um conservante seguro para as maçãs MP durante 16 dias de armazenamento. 


\subsection{Alterações na cor}

Alterações na cor são comuns em frutos MPs, e geralmente ocorrem devido ao dano tecidual provocado pelo descasque e fatiamento, podendo induzir a reações de escurecimento enzimático e não enzimático, fator crítico em maçãs MPs (CHIUMARELLI; HUBINGER, 2012; GUERREIRO et al., 2017; OMS-OLIU et al., 2010).

Segundo Sálvia-Trujillo et al. (2015), a incorporação de OEs em revestimentos pode induzir ao escurecimento dos frutos MPs de duas formas: devido aos compostos fenólicos dos OEs, que podem atuar como substratos para a atividade da polifenoloxidase (PFO) e, pelo aumento da permeabilidade da membrana celular das plantas, que pelos compostos voláteis, pode causar uma maior liberação de PFO e polifenóis do citoplasma da célula, produzindo quinonas que se autopolimerizam para formar pigmentos de cor marrom (SARENGAOWA et al., 2017; TOIVONEN; BRUMMELL, 2008).

O efeito de preservação da cor de maçãs MPs revestidas com adição de OEs foi dependente da concentração de OE aplicada. Nos trabalhos avaliados, as menores concentrações analisadas foram eficientes em prevenir o escurecimento, porém, ao aumentar a concentração de OE no revestimento, houve um pronunciado escurecimento. Rojas-Graü et al. (2007) encontraram resultados que indicam não somente dependência da concentração, mas do tipo de OE empregado no revestimento. Ao longo do armazenamento, foi observado que as maçãs MPs revestidas com 1,5\% de OE de capim-limão sofreram alteração dos parâmetros de cor $L^{*}, a^{*}$ e $b^{*}$ significativamente, enquanto que a adição a 1,0\% do mesmo OE alterou em menor proporção a cor da maçã MP comparado ao controle, sem revestimento. Todavia, as menores alterações na cor das maçãs MPs foram observadas quando OE de vanilina $(0,3$ e $0,6 \%)$ foi incorporado na formulação de revestimento, independente da concentração (ROJAS-GRAÜ et al., 2007). Pode-se afirmar que a incorporação de OEs em concentrações superiores a faixa entre 0,15 e $0,30 \%$ podem causar escurecimento, mesmo na presença de agentes antiescurecimento.

Um estudo realizado em maçãs MPs revestidas com alginato $(2,0 \%)$ incorporado de OEs de canela, cravo e capim-limão $(0,7 \%)$ e seus compostos ativos isolados, cinamaldeído, eugenol e citral $(0,5 \%)$, respectivamente, descreve que a reação de escurecimento foi nitidamente afetada pela adição de maiores concentrações dos OEs ou seus compostos isolados ao revestimento, resultando em danos significativos à integridade do tecido celular (RAYBAUDI-MASSILIA et al., 2008).

Sarengaowa et al. (2017) incorporaram ácido ascórbico (0,01\%) e cloreto de cálcio $(0,02 \%)$ como agentes antiescurecimento em revestimento à base de alginato $(1,29 \%)$ e $\mathrm{OE}$ de tomilho $(0,05,0,35$ e $0,65 \%)$. Apesar do revestimento ter atuado como barreira contra o oxigênio, concentrações de 0,35 e $0,65 \%$ de OE de tomilho aceleraram o escurecimento das maçãs MPs. Isso se deve, provavelmente, a um efeito fitotóxico causado pela maior concentração do OE (SALVIA-TRUJILLO et al., 2015; SÁNCHEZ-GONZÁLEZ et al., 2011).

Por outro lado, Guerreiro et al. (2017) verificaram que menores concentrações dos constituintes ativos dos OEs, eugenol e/ou citral $(0,10$ e $0,15 \%$, ) em ambos os revestimentos avaliados, alginato ou pectina (2,0\%), apresentaram melhores resultados na redução do índice de escurecimento (IE) das maçãs MPs comparado ao controle (sem revestimento e sem compostos ativos). A presença de eugenol $(0,1 \%)$ combinado com o ácido ascórbico (1,0\%) como agente antiescurecimento no revestimento com alginato $(2,0 \%)$, possibilitou um efeito mais pronunciado na 
luminosidade das maçãs MPs. O uso de OE de tomilho em baixas concentrações $(0,05 \%)$ combinado com um revestimento à base de alginato, teve destaque na inibição do escurecimento das maçãs MPs (SARENGAOWA et al., 2017). Analogamente, ao avaliar o uso de revestimentos comestíveis com nanoemulsões de alginato (2,0\%) contendo OE de capim-limão (0,5 e 1,0\%), Sálvia-Trujillo et al. (2015), verificaram que apesar dos mesmos reduzirem a taxa de respiração e produção de etileno, causaram escurecimento da superfície das maçãs MPs. No entanto, na concentração mínima de OE de capim-limão $(0,1 \%)$, não foi observado escurecimento, pois a luminosidade foi superior aos demais tratamentos durante os 15 dias de armazenamento.

\subsection{Firmeza}

A manutenção da firmeza é um dos parâmetros mais importantes da qualidade das maçãs MPs durante o armazenamento, sendo o amolecimento dos tecidos um dos principais problemas que limitam a vida útil dos frutos (SARENGAOWA, 2017; TOIVONEN; BRUMMELL, 2008).

Ainda que a firmeza tenha diminuído para todos os tratamentos, maçãs MPs revestidas com alginato nas concentrações de 1,29\% (SARENGAOWA et al., 2017) e 2,0\% (RAYBAUDI-MASSILIA et al., 2008) exibiram maiores valores de firmeza em relação às amostras não revestidas. Esse comportamento pode ser atribuído à incorporação do cálcio adicionado para induzir a reticulação do alginato no revestimento, o que fortaleceu a ligação molecular entre os constituintes da parede celular, prevenindo a degradação da mesma e minimizando o amolecimento dos frutos (ALANDES et al., 2006; QUILES et al., 2007). A eficácia do cálcio incorporado ao revestimento foi reduzida quando altas concentrações de OE foram adicionadas, resultando em menor firmeza nos frutos revestidos e adicionados de OE de capimlimão ou canela, ambos a 0,7\%, ou citral e cinamaldeído a 0,5\%. Nesse sentido, o amolecimento das maçãs MPs após a aplicação do revestimento de alginato com OEs ou seus compostos ativos (RAYBAUDI-MASSILIA et al., 2008), foi atribuído ao baixo $\mathrm{pH}$ das soluções dos revestimentos, que conforme observado pelos autores podem ter ocasionado a hidrólise do ácido péctico nas paredes dos frutos. Também foi sugerido que a degradação da textura pode ter sido causada pela penetração dos OEs no tecido celular das maçãs MPs, produzindo mudanças estruturais (PONTING; JACKSON; WATTERS, 1971; SÁNCHEZ-GONZÁLEZ et al., 2011).

Rojas-Graü et al. (2007) indicaram que, apesar das excelentes propriedades de firmeza do cálcio, as maçãs MPs revestidas à base de purê de maçã e alginato contendo $1,5 \%$ de OE de capim-limão e $0,5 \%$ de OE de orégano ocasionaram uma redução drástica na firmeza logo nas primeiras horas após a adição, indicando uma rápida degradação da textura. Contudo, as maçãs revestidas com alginato e purê de maçã contendo OE de vanilina $(0,3$ e $0,6 \%)$ mantiveram a firmeza. Já o uso combinado do OE de tomilho $(0,05 \%)$ com o revestimento de alginato mantiveram a maior firmeza durante os 16 dias de armazenamento. Em contrapartida, a consistência das maçãs MPs diminuiu quando tratadas com 0,35 e 0,65\% de OE de tomilho (SARENGAOWA et al., 2017).

A firmeza das maçãs MPs manteve-se praticamente constante ao longo do armazenamento, independente do revestimento aplicado, ou seja, nem o revestimento de alginato, nem a concentração de OE de capim-limão (0,5 e 1,0\%) tiveram influência sobre a textura dos frutos (SÁLVIA-TRUJILLO et al., 2015). Essas diferenças encontradas entre os estudos realizados podem ser justificadas pelos elevados valores iniciais da firmeza das maçãs MPs e pela concentração e tipo de OE 
incorporado nos revestimentos (SOLIVA-FORTUNY et al., 2002). Em geral, todas as combinações dos revestimentos com alginato ou pectina (2,0\%), adicionados de eugenol $(0,1$ e $0,2 \%)$ ou citral $(0,15 \%)$, foram eficientes em manter a firmeza das maçãs MPs. Ao adicionar agentes antiescurecimento, como ácido ascórbico (1,0\%), cloreto de sódio $(0,05 \%)$ e cloreto de cálcio $(1,0 \%)$ foram obtidos valores de firmeza semelhantes e satisfatórios, enquanto a adição de ácido cítrico $(1,0 \%)$ reduziu a firmeza do revestimento à base de pectina (2,0\%) (GUERREIRO et al., 2017).

\subsection{Avaliação sensorial}

Revestimentos comestíveis que têm pouco ou nenhum sabor são desejáveis para prevenir a detecção durante o consumo (LABUZA; CONTRERAS-MEDELLIN, 1981). No entanto, a incorporação de agentes antimicrobianos naturais, como OEs, pode propiciar sabores fortes associados a eles (ROJAS-GRAÜ et al., 2007). Esse fato tem corroborado com a baixa aceitação de frutas MPs com revestimentos adicionado de OEs que apresentam aromas muito característicos e não são compatíveis com o fruto ao qual são adicionados, podendo até mesmo depreciar as características sensoriais do produto.

A formulação à base de purê de maçã e alginato $(2,0 \%)$ por si só não modificou os atributos sensoriais da maçã $M P$, enquanto 0 uso de OEs influenciou significativamente em todos os parâmetros avaliados. Os revestimentos contendo OE de vanilina $(0,3 \%)$ adicionados às maçãs MPs, bem como, os frutos revestidos sem OEs apresentaram maiores escores em termos de qualidade sensorial comparados aos adicionados de OE de capim-limão (1,0\%), que por sua vez, reduziram a aceitabilidade pelo decréscimo dos escores para cor e firmeza na primeira semana de armazenamento (ROJAS-GRAÜ et al., 2007). De acordo com esses autores, os revestimentos comestíveis podem prevenir a perda parcial ou total dos sabores dos alimentos, mantendo, assim, sua qualidade.

A utilização do revestimento de alginato $(2,0 \%)$ não modificou os atributos sensoriais das maçãs MPs, em que os frutos revestidos receberam maiores pontuações de cor, firmeza, sabor e acidez no dia 0. Embora as maçãs MPs revestidas com alginato incorporados de OE de cravo-da-índia $(0,7 \%)$ tenham recebido a menor pontuação para o sabor, os frutos revestidos com alginato e, com alginato adicionados de OE de capim-limão $(0,7 \%)$ foram os preferidos pelos avaliadores após 15 dias de armazenamento (RAYBAUDI-MASSILIA et al., 2008).

No estudo realizado por Guerreiro et al. (2017), após 6 dias de armazenamento, as maçãs MPs revestidas com alginato ou pectina $(2,0 \%)$ apresentaram altas pontuações no painel de sabor e uma boa apreciação sensorial, enquanto os frutos não revestidos e sem adição dos compostos ativos não foram adequados para consumo, obtendo escores inferiores. Devido ao fato dos compostos isolados, eugenol e citral, terem sido adicionados em baixas concentrações $(0,1$ a $0,2 \%)$, os atributos sensoriais não sofreram influência dos mesmos. Assim, tomando como base as características globais e sensoriais de qualidade, o revestimento à base de alginato incorporado com eugenol $(0,1 \%)$, além de ser o preferido pelos avaliadores, foi o que melhor conservou os frutos MPs (GUERREIRO et al., 2017).

A adição de componentes derivados da própria fruta, como o purê de maçã investigado por Rojas-Graü et al. (2007), podem ser aliados para aumentar a aceitabilidade da maçã MP revestida com OEs, em que, de acordo com os autores, o OE de vanilina foi o que mais se destacou em manter as características da maçã MP durante o armazenamento. No entanto, diferentemente da cor, não se pode afirmar qual concentração de OE é melhor para manter a qualidade sensorial, visto que, 
diversos autores encontraram diferentes combinações de revestimentos e OEs que forneceram boa aceitabilidade. Nesse quesito, o parâmetro sabor aparece como fator crucial devido à prevalência de aroma e sabores característicos do OE sobre os da fruta.

\section{Adição de óleos essenciais em revestimentos comestíveis aplicados a melões minimamente processados}

O melão (Cucumis melo L.) é uma fruta amplamente cultivada e consumida em todo o mundo, com excelente potencial para obtenção de produtos MPs, grande parte devido às suas características sensoriais atrativas. Porém, com o processamento, o melão torna-se altamente suscetível ao amolecimento, à perda de água e alteração de cor, além de ter suas reações metabólicas aceleradas, levando ao aumento da taxa respiratória, produção de etileno e crescimento de micro-organismos, o que reduz a sua vida de prateleira (AGUAYO; ESCALONA; ARTÉS, 2004; ARRUDA et al., 2007; RAYBAUDI-MASSILIA; MOSQUEDA-MELGAR; MARTÍN-BELLOSO, 2008; ZAMBRANO-ZARAGOZA et al., 2017).

A seguir será relatada a influência da incorporação de revestimentos comestíveis combinada com OEs ou seus compostos ativos nos atributos, físicos e biológicos, de melões MPs.

\subsection{Avaliação microbiológica}

O efeito da incorporação de OEs de canela, palmarosa e capim-limão $(0,3$ a $0,7 \%)$ ou os seus principais compostos ativos, eugenol, geraniol e citral (0,5\%), respectivamente, no revestimento à base de alginato $(2,0 \%)$ e ácido málico $(2,5 \%)$ aplicado em melão MP foi avaliado por Raybaudi-Massilia, Mosqueda-Melgar e MartínBelloso (2008). Houve maior inibição dos micro-organismos mesófilos e psicrófilos com uso dos revestimentos adicionados dos OEs ou compostos isolados, comparado ao fruto revestido sem OE. Essa inibição pode ser devido à atividade antimicrobiana do ácido málico $(2,5 \%)$ combinado com os OEs ou seus compostos isolados. Uma extensão no prazo de validade foi obtida para o melão MP revestido (9 a 10 dias) comparado ao fruto não revestido (3 dias), demonstrando que o revestimento foi um bom transportador antimicrobiano para o fruto. Contudo, concentrações mais elevadas dos OEs em geral, foram mais eficazes, com destaque para a adição dos compostos ativos a $0,5 \%$ e do OE de palmarosa, efetivo em ambas as concentrações utilizadas $(0,3$ e $0,7 \%)$ que prolongaram a vida útil do melão MP por mais de 21 dias.

Moreira et al. (2014) ao empregarem o revestimento na forma de multicamada à base de quitosana e pectina (ambos a 2,0\%), incorporado de um complexo microencapsulado do composto trans-cinamaldeído e $\beta$-ciclodextrina (2,0\%), constataram que o revestimento foi eficaz na inibição do crescimento de microorganismos aeróbios, psicrófilos, bolores e leveduras em melão MP, na qual apresentaram contagem final quatro vezes inferior aos frutos não revestidos (controle) durante o armazenamento. $O$ uso do revestimento multicamada incorporado do composto trans-cinamaldeído também foi responsável por prolongar a vida útil do melão MP até 15 dias, enquanto que a validade dos frutos controle foi de apenas 7 dias, indicando melhora na qualidade microbiológica.

Ao avaliar o efeito do revestimento comestível aplicado na forma de multicamadas composto por quitosana $(0,5,1,0$ e $2,0 \%)$ e pectina $(0,5,1,0$ e $2,0 \%)$, adicionado do agente antimicrobiano encapsulado trans-cinamaldeído $(1,0,2,0$ e 3,0\%), foi observada uma relação entre a concentração de antimicrobiano e a redução de micro- 
organismos presentes (MARTIÑON et al., 2014). Embora todos os revestimentos com antimicrobianos tenham sido satisfatórios, a incorporação das maiores concentrações do composto trans-cinamaldeído (2,0 e 3,0\%) prolongou a vida útil dos melões MPs em 7 e 10 dias, respectivamente, sendo mais eficazes em inibir o crescimento de bolores e leveduras. O revestimento somente com quitosana não inibiu efetivamente a população de aeróbios, obtendo taxa de crescimento microbiano semelhante ao controle, com vida útil inferior a 4 dias.

Chevalier et al. (2016) investigaram os efeitos da aplicação de revestimento comestível à base de quitosana $(1,0 \%)$ juntamente com argila montmorillonita $(0,3 \%)$ e OE de cravo-da-índia (0,5\%) em melão MP. De acordo com seus resultados, as amostras controle (sem revestimento), bem como, os frutos revestidos somente com quitosana apresentaram valores elevados no crescimento de bolores e leveduras no $3^{\circ}$ dia de armazenamento, diferentemente do que ocorreu com os frutos revestidos adicionadas de montmorillonita e $\mathrm{OE}$, em que o aparecimento dos micro-organismos foi observado a partir do $5^{\circ}$ dia, indicando que o uso do OE de cravo-da-índia junto à montimotillonita foi eficaz em retardar o crescimento microbiano no melão MP e prolongar a vida útil dos frutos em 7 dias.

Em estudo mais recente, foi constatado que revestimentos à base de isolado proteico ácido (IPA) e básico (IPB) de tilápia (1,5\%), adicionados de OE de cravo-da-índia $(1,5 \%)$, proporcionaram menor crescimento de micro-organismos psicrotróficos, bolores e leveduras durante o armazenamento, quando comparado à amostra controle (sem revestimento e OE). O tratamento à base de IPB foi eficaz em aumentar a vida útil do fruto em 12 dias, tornando o melão MP mais seguro para consumo durante mais tempo (CHEVALIER et al., 2018).

\subsection{Atributos de cor}

A mudança de cor é uma das alterações mais importantes nos frutos MPs durante o armazenamento, o que afeta diretamente a percepção de qualidade pelos consumidores (OLIVAS; BARBOSA-CÁNOVAS, 2005). Os revestimentos são notadamente reconhecidos pelas propriedades de barreira ao oxigênio e à água que proporcionam, evitando assim reações que alteram a qualidade dos vegetais revestidos.

A aplicação de concentrações mais elevadas dos OEs de canela, palmarosa e capimlimão $(0,7 \%)$ e dos compostos eugenol e geraniol $(0,5 \%)$, respectivamente, ao revestimento de alginato $(2,0 \%)$ aplicado ao melão $\mathrm{MP}$, ocasionaram redução no índice de brancura (IB) logo após sua aplicação, o que de acordo com Oms-Oliu, Soliva-Fortuny e Martín-Belloso (2008) é associado a um aumento do dano de translucidez, distúrbio fisiológico que torna a polpa do fruto escura e com aspecto vítreo. Entretanto, menores concentrações dos OEs citados $(0,3 \%)$ e citral $(0,5 \%)$, promoveram menor redução ao longo do tempo (RAYBAUDI-MASSILIA; MOSQUEDAMELGAR; MARTíN-BELLOSO, 2008).

O emprego de revestimentos à base de quitosana em concentrações de 0,5 a 2,0\% (CARVALHO et al., 2016; MARTIÑON et al., 2014; MOREIRA et al., 2014) e pectina a 2,0\% (MOREIRA et al., 2014) com adição do composto trans-cinamaldeído (0,5 e $2,0 \%$, auxiliaram na preservação da cor do melão MP, em que a coloração amareloalaranjada da polpa foi mantida evitando o escurecimento oxidativo ou enzimático. Apesar do parâmetro de luminosidade $\left(L^{*}\right)$ ter diminuído no decorrer do tempo, nestes trabalhos, os frutos não revestidos apresentaram superfície com coloração mais escura no final do armazenamento. 
Os revestimentos à base de IPA e IPB de tilápia (1,5\%) adicionados de OE de cravoda-índia (1,5\%) mantiveram a coloração dos melões MPs em comparação aos frutos não revestidos e sem a adição do OE. O uso de antioxidantes proporcionou maior inibição do escurecimento enzimático nos frutos, demonstrado pela menor redução na luminosidade, principalmente quando o revestimento de IPA foi utilizado (CHEVALIER et al., 2018). As propriedades advindas dos OEs incorporados nos revestimentos à base da proteína do peixe, provavelmente, exerceram influência na coloração dos melões MPs.

\subsection{Firmeza}

Em frutas MPs, mudanças na textura são geralmente advindas dos processos de amadurecimento, senescência ou causadas pela perda de massa, responsáveis pelas características indesejáveis dos produtos como, amolecimento da polpa, rompimento celular e aumento da quantidade de suco nos tecidos (BRECHT et al., 2007). Uma alternativa de manutenção da firmeza é a adição de cálcio ao revestimento, uma vez que a adição do composto, promove o aumento da rigidez estrutural da parede celular, além de preservar a integridade funcional e estrutural dos sistemas de membranas (POOVAIAH, 1986).

Segundo Moreira et al. (2014), os frutos revestidos à base de quitosana e pectina $(2,0 \%)$ incorporados de trans-cinamaldeído microencapsulado $(2,0 \%)$ apresentaram valores de firmeza duas vezes maior comparado aos frutos sem revestimento até 0 $15^{\circ}$ dia de armazenamento, resultado associado ao fenômeno de reticulação exercido pelo cloreto de cálcio $(2,0 \%)$.

Por outro lado, a utilização dos OEs de palmarosa e capim-limão $(0,7 \%)$, bem como, seus compostos isolados, geraniol e citral $(0,5 \%)$, respectivamente, diminuíram a firmeza dos frutos em maior proporção que a adição de OE de canela e eugenol. Esse resultado pode ser consequência da ação dos OEs e seus constituintes sobre o tecido celular dos MPs, que possivelmente sofrem alterações estruturais (RAYBAUDIMASSILIA, MOSQUEDA-MELGAR; MARTÍN-BELLOSO, 2008). Embora os OEs de palmarosa, capim-limão e canela tenham componentes ativos e majoritários distintos (geraniol, citral e eugenol, respectivamente), possuem compostos secundários que apresentam efeito sinérgico com os compostos isolados (BURT, 2004). Nesse caso, é importante salientar que os OEs de palmarosa e capim-limão têm geraniol e acetato de geranila em comum, o que pode explicar o comportamento semelhante sobre a firmeza do melão MP.

Carvalho et al. (2016) verificaram que, apesar de ter ocorrido a perda de massa no melão MP revestido com quitosana $(2,0 \%)$ e trans-cinamaldeído $(0,5 \%)$, a firmeza foi mantida durante os 15 dias de armazenamento. O amolecimento dos frutos não revestidos foi associado a uma maior peroxidação lipídica do tecido, visto que, o revestimento atua como uma barreira ao oxigênio necessário para essas reações, e a capacidade antioxidante do trans-cinemaldeído foi atribuída à redução da peroxidação do melão MP revestido e da atividade de enzimas hidrolases envolvidas na dissolução da parede celular.

A adição de lactato ou cloreto de cálcio (2,0\%) à solução de reticulação dos revestimentos à base de alginato (2,0\%) testados por Raybaudi-Massilia, MosquedaMelgar e Martín-Belloso (2008) e de alginato (2,0\%), pectina $(2,0 \%)$ e gelana $(0,5 \%)$ testados por Oms-Oliu, Soliva-Fortuny e Martín-Belloso (2008), impediram o amolecimento dos melões MPs. 


\subsection{Avaliação sensorial}

O uso do revestimento à base de quitosana isolada (1,0\%) e combinada com montmorillonita $(0,3 \%)$ e OE de cravo-da-índia $(0,5 \%)$ foi eficaz em manter as características sensoriais dos melões MPs (CHEVALIER et al., 2016).

Raybaudi-Massilia, Mosqueda-Melgar e Martín-Belloso (2008) relataram que não houve diferenças na aceitação dos frutos revestidos com alginato $(2,0 \%)$ em comparação ao controle, sem adição do revestimento. Inversamente, as características sensoriais de odor e sabor foram afetadas pela incorporação do OE de canela $(0,3$ e $0,7 \%)$, uma vez que menor aceitação do melão MP foi observada comparado à adição de OE de palmarosa ou capim-limão nas mesmas concentrações. Já a percepção da firmeza foi afetada pela incorporação de OE capim-limão logo no primeiro dia, intensificando esse efeito negativo durante o tempo de armazenamento. Entretanto, a adição de OE de palmarosa (0,3\%) ao revestimento, mostrou ser uma alternativa promissora para a conservação, uma vez que manteve as características sensoriais similar ao melão MP não revestido.

Diferentes concentrações do composto antimicrobiano trans-cinamaldeído no revestimento afetaram a aceitação dos melões MPs pelos avaliadores. A adição do composto na concentração máxima avaliada $(3,0 \%)$ foi indesejável, visto que conferiu forte sabor e aroma de canela aos frutos. Em contrapartida, frutos revestidos somente com quitosana $(0,5 \%)$, apresentaram ligeira preferência, grande parte devido ao efeito benéfico em preservar os atributos de cor nos melões. A percepção de textura mudou ao longo do armazenamento, em que no $15^{\circ}$ dia de armazenamento, a aceitabilidade caiu drasticamente pelos avaliadores que detectaram a presença dos revestimentos com ou sem a adição do composto ativo nos frutos. Ainda que os índices gerais tenham indicado maior preferência pelos melões MPs não revestidos e sem 0 composto do $\mathrm{OE}$ de canela, frutos com revestimento multicamada à base de quitosana $(0,5 \%)$ e pectina $(1,0 \%)$ incorporados com $2,0 \%$ de trans-cinamaldeído foram bem aceitos, de modo que mantiveram os atributos sensoriais originais do melão por mais tempo (7 a 9 dias) comparados aos frutos não revestidos (4 dias) (MARTIÑON et al., 2014).

\section{Considerações Finais}

A comercialização de frutas minimamente processadas (MPs) está cada vez mais consolidada em diversas partes do mundo, onde o uso de tecnologias emergentes torna-se fundamental para melhor atender às exigências impostas pelos consumidores. O emprego de revestimentos comestíveis possui grande potencial a ser explorado, visto que, atuam como transportadores de antioxidantes, agentes antiescurecimento e antimicrobianos, a exemplo dos óleos essenciais (OEs) e seus compostos ativos isolados, que auxiliam na extensão da vida útil, de modo a garantir a segurança microbiológica e a qualidade dos frutos MPs. A adição de OEs ou de seus compostos ativos aos revestimentos ocasionaram maior inibição do crescimento de diversos grupos de micro-organismos deteriorantes e patogênicos em maçã e melão MPs. O uso de maiores concentrações de OE ampliou o seu efeito antimicrobiano, dependendo do tipo de óleo adicionado. No entanto, alterações de cor e textura foram observadas mesmo na presença de agentes antiescurecimento e reticulantes nos revestimentos, como ácidos orgânicos e sais de cálcio. Embora os revestimentos exerçam barreira ao oxigênio e vapor de água, a incorporação de OEs em maiores concentrações foi associada ao aumento da reação de escurecimento, peroxidação lipídica e modificações estruturais nos tecidos. A aceitabilidade de frutas MPs revestidas na presença de OEs está condicionada a manutenção de seu sabor e aroma característicos. A partir dos dados coletados, é possível afirmar que o emprego 
em baixas concentrações de OEs, bem como, de seus compostos ativos em revestimentos comestíveis, são eficazes em manter a qualidade geral de maçãs e melões MPs.

Contudo, fica evidente a necessidade e importância de realizar mais estudos que relatem sobre a influência da incorporação de diferentes OEs ou seus componentes ativos isolados, com ênfase nos compostos majoritários e, suas respectivas concentrações em revestimentos comestíveis aplicados em melões e maçãs MPs. O ponto de partida principal consiste em explorar a obtenção de maiores informações acerca da dose ideal a ser adicionada, bem como, seus efeitos, benefícios e possíveis interferências nas principais características dos frutos, tanto do ponto de vista microbiológico quanto de aceitação por parte dos consumidores.

\section{Referências}

AGUAYO, E.; ESCALONA, V. H.; ARTÉS, F. Metabolic behavior and quality changes of whole and fresh processed melon. Journal of Food Science, v. 69, n. 4, p. 148155, 2004. https://doi.org/10.1111/j.1365-2621.2004.tb06356.x.

ALANDES, L. et al. Cell wall stability of fresh-cut fuji apples treated with calcium lactate. Journal of Food Science, v. 71, n. 9, p. S615-S620, 2006. https://doi.org/10.1111/j.1750-3841.2006.00180.x.

ALZAMORA, S. M. et al. Minimally processed foods. In: CABALLERO, B.; FINGLAS, P.; TOLDRA, F. (Eds.) Encyclopedia of Food and Health. Waltham: Academic Press, p. 767-771, 2016.

ARRUDA, M. C. et al. Processamento mínimo de melão. In: MORETTI, C. L. (Ed.). Manual de processamento mínimo de frutas e hortaliças. Brasília: Embrapa Hortaliças, p. 453-464, 2007.

ARTÉS, F; GÓMEZ, P. A.; ARTÉS-HERNÁNDEZ, F. Physical, physiological and microbial deterioration of minimally fresh processed fruits and vegetables. Food Science and Technology International, v. 13, n. 3, p. 177-188, 2007. https://doi.org/10.1177/1082013207079610.

BALDWIN, E. A.; NISPEROS-CARRIEDO; M. O.; BAKER, R. A. Use of edible coatings to preserve quality of lightly (and slightly) processed products. Critical Reviews in Food Science and Nutrition, v. 35, n. 6, p. 509-524, 1995. https://doi.org/10.1080/10408399509527713.

BRECHT, J. K. et al. Alterações metabólicas. In: MORETTI, C. L. (Eds.). Manual de processamento mínimo de frutas e hortaliças. Brasília: Embrapa Hortaliças, p. 453464, 2007.

BURT, S. Essential oils: their antibacterial properties and potential applications in foods - a review. International Journal of Food Microbiology, v. 94, p. 223-253, 2004. https://doi.org/10.1016/j.ijfoodmicro.2004.03.022.

CAO, N.; FU, Y.; HE, J. H. Mechanical properties of gelatin films cross-linked, respectively, by ferulic acid and tannin acid. Food Hydrocolloids, v. 21, n. 4, p. 575584, 2007. https://doi.org/10.1016/j.foodhyd.2006.07.001. 
CARVALHO, R. L. et al. Chitosan coating with trans-cinnamaldehyde improves structural integrity and antioxidant metabolism of fresh-cut melon. Postharvest $\begin{array}{lllll}\text { Biology and Technology, v. 113, p. 29-39, } 2016 . & \end{array}$ https://doi.org/10.1016/j.postharvbio.2015.11.004.

CHEVALIER, R. C. et al. Utilização de revestimento comestível à base de quitosana para aumentar a vida útil de melão minimamente processado. Journal of Bioenergy and Food Science, v. 3, n. 3, p. 130-138, 2016. https://doi.org/ 10.18067/jbfs.v3i3.101.

CHEVALIER, R. C. et al. Obtaining protein isolate of tilapia (Oreochromis niloticus) and its application as coating in fresh-cut melons. Journal of Food Safety, v. 38:e12496, n. 5, p. 1-10, 2018. https://doi.org/10.1111/jfs.12496.

CHIUMARELLI, M.; HUBINGER, M. D. Stability, solubility, mechanical and barrier properties of cassava starch-Carnauba was edible coating to preserve fresh-cut $\begin{array}{llllll}\text { apples. Food Hydrocolloids, } & \text { v. 28, p. 59-67, } 2012 .\end{array}$ https://doi.org/10.1016/j.foodhyd.2011.12.006.

COSTA, A. P. D. et al. Minimally processed beetroot waste as an alternative source to obtain functional ingredients. Journal of Food Science and Technology, v. 18, n. 66, p. 1-9, 2017. https://doi.org/10.1007/s13197-017-2642-4.

FAGUNDES, C. Estudo cinético do processamento mínimo de maçã (Malus domestica B.) var. Gala: influência da temperatura na taxa respiratória e nos parâmetros físico-químicos e sensoriais. 2009. 113 f. Dissertação (Mestrado em Engenharia de Alimentos) - Escola de Química e Alimentos, Universidade Federal de Santa Catarina, Florianópolis, 2009.

FONTES, L. C. B. et al. Conservação de maçã minimamente processada com o uso de películas comestíveis. Ciência e Tecnologia de Alimentos, v. 28, n. 4, p. 872-880, 2008. Disponível em: <https://www.scielo.br/pdf/cta/v28n4/a17v28n4.pdf>. Acesso 29 dez. 2020.

FREIRE, C. J. S. et al. A cultura da maçã. Brasília: Embrapa, 1994. 107 p.

FRIEDMAN, M.; HENIKA, P. R.; MANDRELL, R. E. Bactericidal activities of plant essential oils and some of their isolated constituents against Campylobacter jejuni, Escherichia coli, Listeria monocytogenes and Salmonella enterica. Journal of Food Protection, v. 65 , n. 10 , p. 1545-1560, 2002. https://doi.org/10.4315/0362-028x65.10.1545.

GUERREIRO, A. C. et al. The effect of edible coating on the nutritional quality of 'Bravo de Esmolfe' fresh-cut apple through shelf life. LWT - Food Science and Technology, v. 75, p. 210-219, 2017. https://doi.org/10.1016/j.Iwt.2016.08.052.

KLUGE, R. A. et al. Processamento mínimo de hortaliças: princípios e práticas. Piracicaba: Universidade de São Paulo, 2016. 85 p.

LABUZA, T. P.; CONTRERAS-MEDELLIN, R. Prediction of moisture protection requirements for foods. Cereal Foods World, v. 26, n. 7, p. 335-343, 1981.

MALDONADO, R. R. et al. Aplicação de biofilme comestível em maçãs minimamente processadas armazenadas sob refrigeração. Foco: Caderno de Estudos e Pesquisas, n. 10, p. 60-80, 2016. Disponível em: 
<http://www.revistafoco.inf.br/index.php/FocoFimi/article/view/88>. Acesso 29 dez. 2020.

MARTIÑON, M. E. et al. Development of a multilayered antimicrobial edible coating for shelf-life extension of fresh-cut cantaloupe (Cucumis melo L.) stored at $4{ }^{\circ} \mathrm{C}$. LWT Food Science and Technology, v. 56, p. 341-350, 2014. https://doi.org/10.1016/j.Iwt.2013.11.043.

MOREIRA, S. P. et al. Freshness retention of minimally processed melon using different packages and multilayered edible coating containing microencapsulated essential oil. International Journal of Food Science and Technology, v. 49, p. 21922203, 2014. https://doi.org/10.1111/ijfs.12535.

MORETTI, C. L. Manual de processamento mínimo de frutas e hortaliças. Brasília: Embrapa Hortaliças, 2007. 531 p.

NYCHAS, G. J. E.; TASSOU, C. C.; SKANDAMIS, P. Antimicrobials from herbs and spices. In: ROLLER, S. M. (Eds.), Natural antimicrobials for the minimal processing of foods. New York: CRC Press, p. 176-200, 2003.

OLIVAS, G. I.; BARBOSA-CÁNOVAS, G. V. Edible coatings for fresh-cut fruits. Critical Reviews in Food Science and Nutrition, v. 45, p. 657-670, 2005. https://doi.org/10.1080/10408690490911837.

OMS-OLIU, G.; SOLIVA-FORTUNY, R.; MARTÍN-BELLOSO, O. Using polysaccharidebased edible coating to enhance quality and antioxidant properties of fresh-cut melon. LWT - Food Science and Technology, v. 41, p. 1862-1870, 2008. https://doi.org/10.1016/j.Iwt.2008.01.007.

OMS-OLIU, G. et al. Recent approaches using chemical treatments to preserve quality of fresh-cut fruit: a review. Postharvest Biology Technology, v. 57, p. 139-148, 2010. https://doi.org/10.1016/j.postharvbio.2010.04.001.

PICCHIONI, G. A. et al. Membrane lipid metabolism, cell permeability, and ultrastructural changes in lightly processed carrots. Journal of Food Science, v. 59, n.3, p.597-601, 1994. https://doi.org/10.1111/j.1365-2621.1994.tb05571.x.

PONTING, J. D.; JACKSON, R.; WATTERS, G. Refrigerated apple slices: effects of $\mathrm{pH}$, sulfites and calcium on texture. Journal of Food Science, v. 36, p. 349-350, 1971. https://doi.org/10.1111/j.1365-2621.1971.tb04059.x.

POOVAIAH, B. W. Role of calcium in prolonging storage of fruits and vegetables. Food Technology, p. 86-89, 1986.

QUILES, A. et al. Effect of calcium propionate on the microstructure and pectin methylesterase activity in the parenchyma of fresh-cut Fuji apples. Journal of the Science of Food and Agriculture, v. 87, p. 511-519, 2007. https://doi.org/10.1002/jsfa.2749.

RAYBAUDI-MASSILIA, R. M.; MOSQUEDA-MELGAR, J.; MARTÍN-BELLOSO, O. Edible alginate-based coating as carrier of antimicrobials to improve shelf-life and safety of fresh-cut melon. International Journal of Food Microbiology, v. 121, p. 313-327, 2008. https://doi.org/10.1016/j.ijfoodmicro.2007.11.010. 
RAYBAUDI-MASSILIA, R. M.; ROJAS-GRAÜ, M. A.; MOSQUEDA-MELGAR, J.; OLGA MARTÍN-BELLOSO, O. Comparative study on essential oils incorporated into an alginate-based edible coating to assure the safety and quality of fresh-cut fuji apples. Journal of Food Protection, v. 71, n. 6, p. 1150-1161, 2008. https://doi.org/10.4315/0362-028x-71.6.1150.

ROJAS-GRAÜ, M. A. et al. Apple puree-alginate edible coating as carrier of antimicrobial agents to prolong shelf-life of fresh-cut apples. Postharvest Biology and $\begin{array}{lllll}\text { Technology, } & \text { v. } & 45, & \text { p. } & 254-264,\end{array}$ https://doi.org/10.1016/j.postharvbio.2007.01.017.

ROJAS-GRAÜ, M. A.; TAPIA, M. S.; MARTÍN-BELLOSO, O. Using polysaccharidebased edible coatings to mantain quality of fresh-cut fuji apples. LWT - Food and $\begin{array}{llllll}\text { Science } & \text { Technology, } & \text { v. } & 41, & \text { p. }\end{array}$ https://doi.org/10.1016/j.Iwt.2007.01.009.

SALVIA-TRUJILLO, L. et al. Use of antimicrobial nanoemulsions as edible coatings: Impact in safety and quality atributes of fresh-cut Fuji apples. Postharvest Biology $\begin{array}{llllll}\text { and Technology, } & \text { v. } & 105, & \text { p. } & 8-16,\end{array}$ https://doi.org/10.1016/j.postharvbio.2015.03.009.

SÁNCHEZ-GONZÁLEZ, L. et al. Use of essential oils in bioactive edible coatings. Food Engineering Reviews, v. 3, p. 1-16, 2011. https://doi.org/10.1007/s12393-0109031-3.

SANTOS, N. S. T. et al. Efficacy of the application of a coating composed of chitosan and Origanum vulgare L. essential oil to control Rhizopus stolonifer and Aspergillus niger in grapes (Vitis labrusca L.). Food Microbiology, v. 32, p. 345-353, 2012. https://doi.org/10.1016/j.fm.2012.07.014.

SARENGAOWA et al. Effect of thyme oil-alginate-based coating on quality and microbial safety of fresh-cut apples. Journal of the Science of Food and Agriculture, v. 98 , n. 6 , p. 2302-2311, 2017. https://doi.org/10.1002/jsfa.8720.

SOLIVA-FORTUNY, R. C. et al. Effect of minimal processing on the textural and structural properties of fresh-cut pears. Journal of the Science of Food and Agriculture, v. 82, p. 1682-1688, 2002. https://doi.org/10.1002/jsfa.1248.

TOIVONEN, P. M. A.; BRUMMELL, D. A. Biochemical bases of appearance and texture changes in fresh-cut fruits and vegetables. Postharvest Biology and Technology, v. 48, p. 1-14, 2008. https://doi.org/10.1016/j.postharvbio.2007.09.004.

ZAMBRANO-ZARAGOZA, M. L. et al. The release kinetics of $\beta$-carotene nanocapsules/xanthan gum coating and quality changes in fresh-cut melon (Cantaloupe). Carbohydrate Polymers, v. 157, p. 1874-1882, 2017. https://doi.org/10.1016/j.carbpol.2016.11.075.

\section{Autores}

Renata Fialho Teixeira ${ }^{1, *}$, Caroline Dellinghausen Borges 
1. Curso de Pós-Graduação Lato Sensu em Ciência dos Alimentos, Centro de Ciências Químicas, Farmacêuticas e de Alimentos, Universidade Federal de Pelotas, Campus Capão do Leão, 96010-900, Pelotas, RS, Brasil.

2. Centro de Ciências Químicas, Farmacêuticas e de Alimentos, Universidade Federal de Pelotas, Campus Capão do Leão, 96010-900, Pelotas, RS, Brasil.

*Autor para correspondência: renatafialhot@gmail.com 